\title{
Vesícula multiseptada, a propósito de un caso de diagnóstico incidental
}

\section{Multiseptate Gallbladder: Case Report of an Incidental Diagnosis}

\author{
María Eugenia Lúcia $C^{1}$ Raimundo Bustos Knight ${ }^{2}$ \\ J L. Parraguez $\mathrm{C}^{4}$ \\ ${ }^{1}$ Servicio de Radiología, Clínica Santa María, Santiago, Chile \\ 2 Médico Cirujano, Clinica Davila, Santiago, Chile \\ 3 Departamento de Radiología, Universidad de Los Andes, Santiago, \\ Chile \\ ${ }^{4}$ Hospital San Agustín, La Ligua, Chile
}

Rev Argent Radiol 2021;85:46-48.

Estimados Editores,

Presentamos un caso de diagnóstico incidental.

La vesícula multiseptada fue descrita por primera vez en el año 1963 por Simon y Tandon. ${ }^{1}$ Desde entonces, hasta el año 2016, 63 casos fueron descritos en la literatura. ${ }^{2}$

Las malformaciones congénitas de la vesícula pueden ser clasificadas según su localización, morfología, tamaño y número, siendo la primera la de mayor frecuencia. ${ }^{3}$

Dentro de las anomalías de forma, se encuentra la vesícula multiseptada, un hallazgo poco frecuente. Se han reportado casos como hallazgo aislado o también asociado a otras malformaciones, como quistes coledocianos, ectopia vesicular, malformaciones de la vía biliar o hipoplasia vesicular. $^{3-7}$

Describimos el caso de un paciente asintomático que, en contexto de un examen médico preventivo, fue diagnosticado con una vesícula multiseptada.

Se trata de un paciente de sexo masculino de 54 años de edad que realizó un ultrasonido (US) abdominal. No se describen síntomas ni alteración de los exámenes de laboratorio.

Se realizó un US de abdomen con un transductor convexo $6 \mathrm{C} 1 \mathrm{HD}$ de $1,5-5,5 \mathrm{MHz}$ de frecuencia (Acuson S2000, Siemens). Se constató una vesícula única, de pared fina, tamaño normal (5,6 centímetros), con múltiples imágenes
Rosario Valdés $\mathrm{O}^{3}$ Marcela Moraga $\mathrm{L}^{4}$

Address for correspondence Raimundo Bustos Knight, Las Nieves, 158, Vitacura, Santiago, Chile,

(e-mail: raimundobustosk@gmail.com).

ecogénicas lineales compatibles con septos (- Fig. 1), los que no muestran estructuras vasculares detectables al estudio Doppler color, sin evidencia de cálculos, con aspecto de panal de abejas. La vía biliar intra y extrahepática se encuentra de calibre normal (-Fig. 2).

Existe escasa literatura acerca de ese tema. La mayoría de los estudios publicados corresponden a reportes de casos, el primero de ellos en el año 1963, por Simon y Tandon. ${ }^{1}$ Hasta el año 2011, 44 casos habían sido reportados, con una razón hombre mujer de 1:2 y una edad media de presentación de 28,6 años (rango entre 15 días y 70 años). ${ }^{8}$

Si bien es cierto que es una malformación muy poco frecuente, es importante tenerla en consideración. Se han descrito casos de pacientes que consultan por dolor abdominal en hipocondrio derecho y otros diagnosticados incidentalmente, como ocurrió en nuestro caso. La causa del dolor no está clara. Sin embargo, se postula que estaría dada por la dificultad al vaciamiento biliar entre los estrechos canales entre septos, con estasis y vaciamiento incompleto de la misma. ${ }^{9}$

Su etiopatogenia también es incierta. Según la principal hipótesis, propuesta por Simon y Tandon, estaría dada por una alteración del proceso de vacuolización de la vesícula en formación (inicialmente sólida), proceso que ocurre normalmente alrededor de las ocho semanas de gestación.

(C) 2020. Asociación Civil Sociedad Argentina de Radiología and Federacion Argentina de Asociaciones de Radiología, Diagnóstico por Imágenes y Terapia Radiante. All rights reserved.

This is an open access article published by Thieme under the terms of the Creative Commons Attribution-NonDerivative-NonCommercial-License, permitting copying and reproduction so long as the original work is given appropriate credit. Contents may not be used for commercial purposes, or adapted, remixed, transformed or built upon. (https://creativecommons.org/ licenses/by-nc-nd/4.0/)

Thieme Revinter Publicações Ltda., Rua do Matoso 170, Rio de Janeiro, RJ, CEP 20270-135, Brazil 

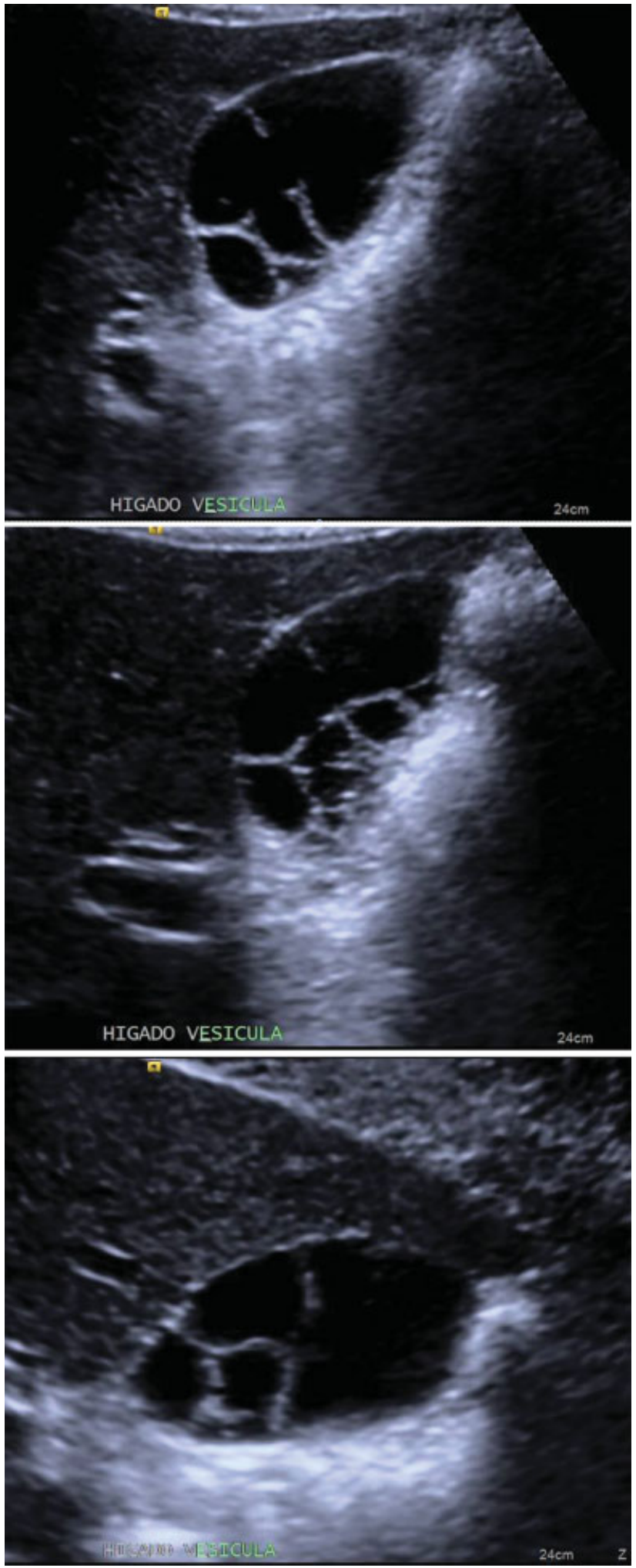

Fig. 1 Vesícula única, con finos septos en su interior, de aspecto en "panal de abejas."

Bhagavan y col., ${ }^{6}$ postularon que esa malformación sería el resultado del crecimiento acelerado de la vesícula embriológica respecto del lecho vesicular y peritoneo.

Los hallazgos clásicamente descritos no difieren de lo observado en nuestro caso: una vesícula única, de tamaño

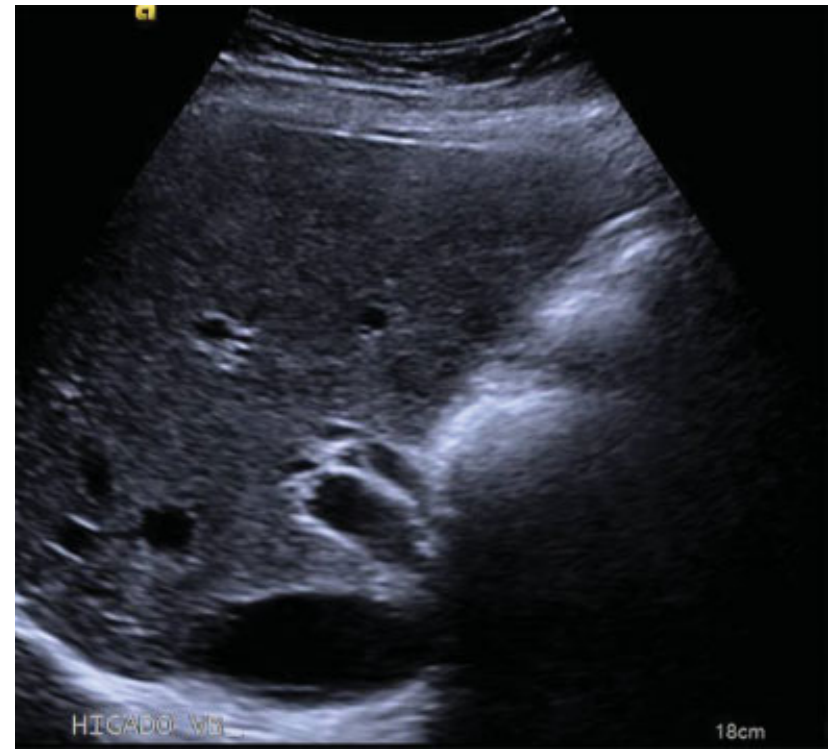

Fig. 2 Vía biliar de calibre normal.

normal, contornos lobulados, septos internos finos y aspecto de panal de abeja.

Dentro del diagnóstico diferencial es importante considerar la enfermedad hidatídica de quistes con vesículas hijas, colecistitis enfisematosa con desprendimiento de membranas desde la pared y algunos casos de colesterolosis polipoidea. Para ello, es fundamental considerar la clínica del paciente, estudios de laboratorio y antecedentes del mismo. Una pared vesicular normal en la vesícula multiseptada nos permitirá descartar algunos diagnósticos.

Para el estudio de esos pacientes, se ha descrito la utilidad del US, de la tomografía computada (TC) de abdomen, de la colangiopancreatografía retrógrada endoscópica (ERCP), de las imágenes con Tecnecio-99 (Tc99) (SPECT) y de la colangiografía por resonancia magnética (RM).

En resumen, planteamos el caso de un paciente asintomático, con una malformación poco frecuente de la vesícula, multiseptada, sin otras malformaciones asociadas. Como primera posibilidad de estudio diagnóstico postulamos el US, por ser una técnica rápida, accesible, de bajo costo y que permite tener excelentes imágenes de la vesícula. Sin embargo, para descartar eventuales malformaciones asociadas, muchas veces será necesario complementar el estudio, idealmente con una RM.

\section{Confidencialidad de los Datos}

El autor declara que ha seguido los protocolos de su centro de trabajo sobre la publicación de datos de pacientes y que todos los pacientes incluidos en el estudio han recibido información suficiente y han dado su consentimiento informado por escrito para participar en dicho estudio.

\section{Conflicto de Intereses}

Los autores del trabajo declaran no tener ningún conflicto de intereses. 
48 Vesícula multiseptada, a propósito de un caso de diagnóstico incidental Lúcia C y col

\section{Bibliografía}

1 Simon M, Tandon BN. Multiseptate gallbladder. A case report. Radiology. 1963;80:84-86

2 Aydin E, Avar Aydin PÖ. Multiseptate Gallbladder: What to Do? Review of the Literature. Turkiye Klinikleri J Pediatr. 2016;25(04): 187-200

3 Türkvatan A, Erden A, Celik M, Olçer T. Ectopic hypoplastic and multiseptate gallbladder with coexisting choledochal cyst: evaluation with sonography and magnetic resonance cholangiopancreaticography. J Clin Ultrasound. 2006;34(02): 88-91

4 Pery M, Kaftori JK, Marvan H, Sweed Y, Kerner H. Ultrasonographic appearance of multiseptate gallbladder: report a case with coexisting choledochal cyst. J Clin Ultrasound. 1985;13(08):570-573
5 Tan CE, Howard ER, Driver M, Murray-Lyon IM. Noncommunicating multiseptate gall bladder and choledochal cyst: a case report and review of publications. Gut. 1993;34(06):853-856

6 Bhagavan BS, Amin PB, Land AS, Weinberg T. Multiseptate gallbladder. Embryogenetic hypotheses. Arch Pathol. 1970;89(04):382-385

7 Jena PK, Hardie RA, Hobsley M. Multiseptate hypoplastic gallbladder. Br J Surg. 1977;64(03):192-193

8 Wanaguru D, Jiwane A, Day AS, Adams S. Multiseptate gallbladder in an asymptomatic child. Case Rep Gastrointest Med. 2011; 2011:470658

9 Strauss S, Starinsky R, Alon Z. Partial multiseptate gallbladder: sonographic appearance. J Ultrasound Med. 1993;12(04): 201-203 